\title{
Fat fibrosis: friend or foe?
}

\author{
Ritwik Datta, ${ }^{1}$ Michael J. Podolsky, ${ }^{1,2,3}$ and Kamran Atabai ${ }^{1,2,3}$ \\ ${ }^{1}$ Cardiovascular Research Institute, '2Lung Biology Center, and ${ }^{3}$ Department of Medicine, University of California, \\ San Francisco, San Francisco, California, USA.
}

\begin{abstract}
At the simplest level, obesity is the manifestation of an imbalance between caloric intake and expenditure; however, the pathophysiological mechanisms that govern the development of obesity and associated complications are enormously complex. Fibrosis within the adipose tissue compartment is one such factor that may influence the development of obesity and/or obesityrelated comorbidities. Furthermore, the functional consequences of adipose tissue fibrosis are a matter of considerable debate, with evidence that fibrosis serves both adaptive and maladaptive roles. Tissue fibrosis itself is incompletely understood, and multiple cellular and molecular pathways are involved in the development, maintenance, and resolution of the fibrotic state. Within the context of obesity, fibrosis influences molecular and cellular events that relate to adipocytes, inflammatory cells, inflammatory mediators, and supporting adipose stromal tissue. In this Review, we explore what is known about the interplay between the development of adipose tissue fibrosis and obesity, with a view toward future investigative and therapeutic avenues.
\end{abstract}

\section{Introduction}

Obesity is a worldwide epidemic with multiple metabolic complications, including hypertension, hyperlipidemia, ectopic lipid deposition, and insulin resistance (1-7). The development of obesity is associated with enlargement of adipose tissue compartments in response to chronic positive calorie balance. Adipose tissue expansion occurs dynamically through adipocyte hypertrophy and/or hyperplasia (8-15) and requires continuous extracellular matrix (ECM) remodeling to accommodate this expansion. Additionally, the matrix itself may promote differentiation of progenitor cells into adipocytes to accommodate further fat storage. Whole-body metabolic homeostasis depends on how adipose tissue remodels in response to excess calorie intake $(16,17)$. Maintenance of a high degree of flexibility in the ECM network would seem to be a prerequisite for healthy adipose tissue. Yet, the specific role of adipose tissue fibrosis, defined here as excess deposition of potentially pathological ECM, in the development of obesity is still debatable. Progression from the lean to the obese state is often accompanied by decreased ECM flexibility due to pericellular collagen deposition. However, the significance of this development is unclear. Despite extensive research, the mechanisms by which adipose tissue fibrosis modulates obesity-associated metabolic changes remain unresolved. The metabolic outcomes associated with fibrosis may also depend on which fat depots are affected. Furthermore, conflicting data from human and mouse models of obesity add further complexity to understanding adipose tissue metabolic phenotypes. In this Review, we examine the constituents and cellular sources of ECM in adipose tissue in the lean and obese states, the role of ECM molecules in adipocyte differentiation, and the effect of ECM remodeling and the development of adipose tissue fibrosis in modulating metabolic homeostasis in the obese state.

\section{Components of adipose tissue ECM}

Conflict of interest: The authors have declared that no conflict of interest exists.

Published: October 4, 2018

\section{Reference information:} JCI Insight. 2018;3(19):e122289. https://doi.org/10.1172/jici. insight.122289.
One consideration when examining the relationship between adipose tissue fibrosis and metabolic homeostasis is whether the molecular constituents of fibrotic adipose tissue are qualitatively or quantitatively different than in other tissues prone to fibrosis. Although adipose tissue ECM has similar protein content as other tissues, the relative quantity and molecular assembly of ECM proteins differ in the adipose compartment (18). Moreover, relative ECM protein quantities in adipose tissues of lean and obese individuals vary significantly (19). Histologically, the adipose compartment is a loose connective tissue where collagens compose most of the noncell tissue mass. In rodents, the collagenous matrix is more developed in subcutaneous adipose tissue than in visceral adipose tissue, with some strain-specific variations $(20,21)$. 
Proteomic analysis of rodent adipose tissue has revealed the presence of 20 subunits of 12 collagens (22-28). Type I collagen fibrils provide the major structural framework of adipose tissue and are present at higher concentrations in subcutaneous fat compared with visceral fat (20). Type III collagen expression is relatively low in murine visceral adipose tissue (29). Similar to other tissues of mesenchymal origin, type IV collagen forms the basal lamina surrounding the adipocytes (30-32). Type II, type IX, and type XVIII collagens are generally thought to be cartilage specific but are expressed at low levels in adipose tissues $(20,33)$. Type XVIII collagen is a structurally complex protein often considered a basement membrane proteoglycan that also exhibits some properties of collagens (34) and has been shown to support adipocyte progenitor differentiation and maintenance of the differentiated state (35).

Type VI collagen expression seems to be somewhat specific to adipose tissue and is more highly expressed in visceral fat pads than subcutaneous adipose tissues $(20,29)$. Type VI collagen is microfibrillar, has extensive disulfide cross-links, and is interwoven with other collagens, including type I (36) and type XIV (37). Type VI collagen may function as a cellular anchor by attaching cells to the basal lamina via type IV collagen (38). Type VI collagen has been shown to interact with other ECM proteins, such as fibronectin (39), fibulin (40), lumican (41), matrillin (42), heparin, and hyaluronan (43, 44); the proteoglycan decorin (45); and other cell surface receptors (46-48). These interactions are critical in organizing the three-dimensional (3D) tissue architecture and likely influence intracellular signaling pathways, as described in peripheral nervous system hypermyelination (49) and skin tissue fibrosis (50).

Several adipose tissue collagens are differentially expressed in obesity. Type VI collagen expression in visceral adipose tissue is increased with obesity $(29,51)$, and COL $4 A 1$ gene expression in human subcutaneous adipose tissue positively correlates with obesity-associated insulin resistance (52). Increased coexpression of type $\mathrm{V}$ and IV collagens with other matrix components, such as syndecan and lumican, during obesity development has also been described (53).

Several other ECM components, such as secreted protein acidic and rich in cysteine $(54,55)$, biglycan (56), heparan sulfate proteoglycans $(57,58)$, aggrecan (59), entactin (60), laminin (60-62), and extendin-4 $(63,64)$, also have described roles in adipogenesis. In this Review, we will focus mainly on the involvement of collagens and collagen-cleaving enzymes in obesity-associated metabolic dysfunction.

\section{Cellular origin of ECM in obese adipose tissue}

Adipocyte progenitors, adipocytes, fibroblasts, and myofibroblasts produce most, if not all, collagens expressed in adipose tissue. Other cell types, including macrophages, are also important regulators of ECM production in adipocytes. However, the contribution of these cell types to adipose compartment ECM production is less established.

In adipose tissue, maximal collagen production occurs during the early stages of white adipose tissue (WAT) differentiation $(27,60)$. Once differentiation is complete and the WAT compartment is fully developed, ECM organizational changes predominate (65) and associate with a steady decline in type V and VI collagen $(66,67)$. The subsequent development of obesity is associated with increased ECM production $(19,29)$. Of note, total adipose tissue collagen in a group of overweight and normal-weight children inversely correlated with BMI and age, with little evidence of type VI collagen staining in fibrotic areas (68).

Interestingly, adipocyte progenitors accumulate in areas of fibrosis within the WAT of obese individuals (69). Furthermore, procollagen I and II transcripts are elevated in adipocyte progenitors and then decline with cell differentiation to adipocytes in culture (67). Increased collagen production has also been associated with increased expression of cell proliferation markers, such as cyclin D1, in adipocyte progenitors $(69,70)$, suggesting that maintenance of a pool of undifferentiated adipocyte progenitors with high proliferative capacity is important for collagen production.

Adipocyte progenitors likely consist of multiple subsets with different functional roles. For example, Marcelin et al. showed that PDGFR $\alpha^{+}$adipocyte progenitors acquire myofibroblast phenotypes in obese adipose tissue (71). Upon high-fat diet (HFD) challenge, PDGFR $\alpha^{+}$adipocyte progenitors showed not only increased expression of ECM genes but also upregulated expression of profibrotic and proinflammatory cytokines. A small subset of PDGFR $\alpha^{+}$progenitors express high levels of CD9, and these CD9 ${ }^{\text {hi }}$ PDGFR $\alpha^{+}$cells have increased proliferative properties along with increased expression of ECM genes and inflammatory markers compared with $\mathrm{CD} 9^{\text {lo }} \mathrm{PDGFR} \alpha^{+}$cells. Additionally, compared with control HFD-fed animals, HFD-fed Pdgfra ${ }^{\text {D842V }}$-knockin mice, which have increased tyrosine kinase activity specifically in Pdgfra-expressing cells, exhibited increased ECM gene expression $(71,72)$. Interestingly, in 
humans, CD9hi progenitor cells in omental WAT, one of the main visceral fat depots, are associated with insulin resistance in obesity (71).

Fibroblasts and myofibroblasts are considered the dominant producers of ECM in other fibrosis-prone tissues (73-75), but little is known about their role in adipose tissue fibrosis. Adipocyte progenitors can differentiate into myofibroblasts, which can then drive collagen synthesis during the development and progression of obesity (76). Although adipocytes do not produce large amounts of ECM under normal conditions, they can dedifferentiate in culture to cells with a fibroblast-like morphology, with increased secretion of matrix remodeling proteins and cytokines, such as IL-6, IL-8, and VEGF (77). It is possible that dedifferentiation of adipocytes into adipocyte progenitors with a fibroblast-like appearance may play an important role in the development of fibrosis during obesity.

Adipocytes can also contribute to ECM production indirectly by affecting other cell types. In obesity, hypertrophic adipocytes can become hypoxic due to increased distance from nearby blood vessels. The stress of hypoxia can in turn lead to the release of chemoattractants, such as monocyte chemoattractant protein-1, that trigger macrophage infiltration of WAT (78-80). Infiltrating macrophages may in turn release signals that attract fibroblasts and inhibit differentiation of adipocyte progenitors. Halberg et al. generated mice that express human dominant-active HIF-1 $\alpha$ under the control of adipocyte-specific aP2 promoter to validate the effect of adipocyte hypoxia on adipose tissue fibrosis. These mice showed upregulated expression of ECM-related genes, including type I, III, and VI collagens; fibronectin; and elastin (78). Thus, in the setting of tissue hypoxia, adipocyte progenitors and fibroblasts exposed to activated macrophages secrete ECM, thereby promoting fibrosis during the development of obesity. In contrast, some recent studies have shown that despite lower adipose tissue blood flow, subcutaneous adipose tissue in obese human patients exhibits hyperoxia $(81,82)$. Adipose tissue hyperoxia is associated with mitochondrial dysfunction, leading to lower oxygen consumption, secretion of chemoattractants, and inflammation (81), all of which may play important roles in regulating adipose tissue fibrosis.

Several cytokines have well-defined roles in modulating adipocyte progenitor differentiation and, therefore, collagen production. TNF- $\alpha$ inhibits transcription of a set of adipocyte-specific genes, resulting in dedifferentiation of adipocytes, as evident from the loss of intracellular lipid droplets $(67,83)$. Treatment of differentiated adipocytes with TNF- $\alpha$ causes accumulation of procollagen mRNAs (50). Expression of TGF- $\beta$, a master regulator of fibrosis, declines with the differentiation of adipocyte progenitors to adipocytes (67). TGF- $\beta$ inhibits differentiation of adipocytes and promotes collagen production $(67,69)$. Adipocyte progenitors, macrophages, and fibroblasts are all potential sources of these cytokines in adipose tissue.

Obesity is associated with macrophage accumulation in adipose tissue $(84,85)$. The contribution of macrophages to ECM production likely occurs through effects on other cell types (69). Treatment of differentiated adipocytes with conditioned media produced by macrophages isolated from obese human adipose tissue causes a marked decrease in expression of adipogenic factors, such as PPAR $\gamma$ and C/EBP, and promotes inflammation through increased NF- $\kappa$ B activity and IL-6 expression (70). Blocking of TNF- $\alpha$ in conditioned media from macrophages successfully prevents inflammatory activation of adipocytes (70). ECM gene expression also increases in adipocyte progenitors exposed to inflammatory cytokines from macrophages $(69,70)$. Potential sources that contribute to increased collagen deposition in obese adipose tissue are summarized in Figure 1.

\section{Collagens and collagen-cleaving enzymes in adipocyte differentiation and obesity development}

ECM remodeling is a prerequisite for adipocyte differentiation in the initial phases of obesity, suggesting that ECM molecules themselves may directly regulate adipocyte progenitor differentiation (86). Moreover, enzymes that modify ECM proteins also seem to help control adipocyte progenitor and adipocyte biology through their actions on ECM proteins and other substrates. In this section, we explore the evidence that supports these hypotheses (see Table 1), with the caveat that global deletion of these enzymes has pleiotropic effects (including on matrix-independent functions), somewhat limiting interpretability of the evidence (87-90).

Green and Meuth measured proline hydroxylation in 3T3-L1 adipocyte progenitors and 3T3-M2 cells (a 3T3 cell line that does not store fat) to estimate the rate of collagen synthesis (91). In 3T3-M2 cells, the collagen synthesis rate was $50 \%$ of the rate in 3T3-L1 cells, suggesting a correlation between collagen synthesis and fat storage (91). Inhibition of collagen synthesis with a competitive inhibitor of prolyl hydroxylase 


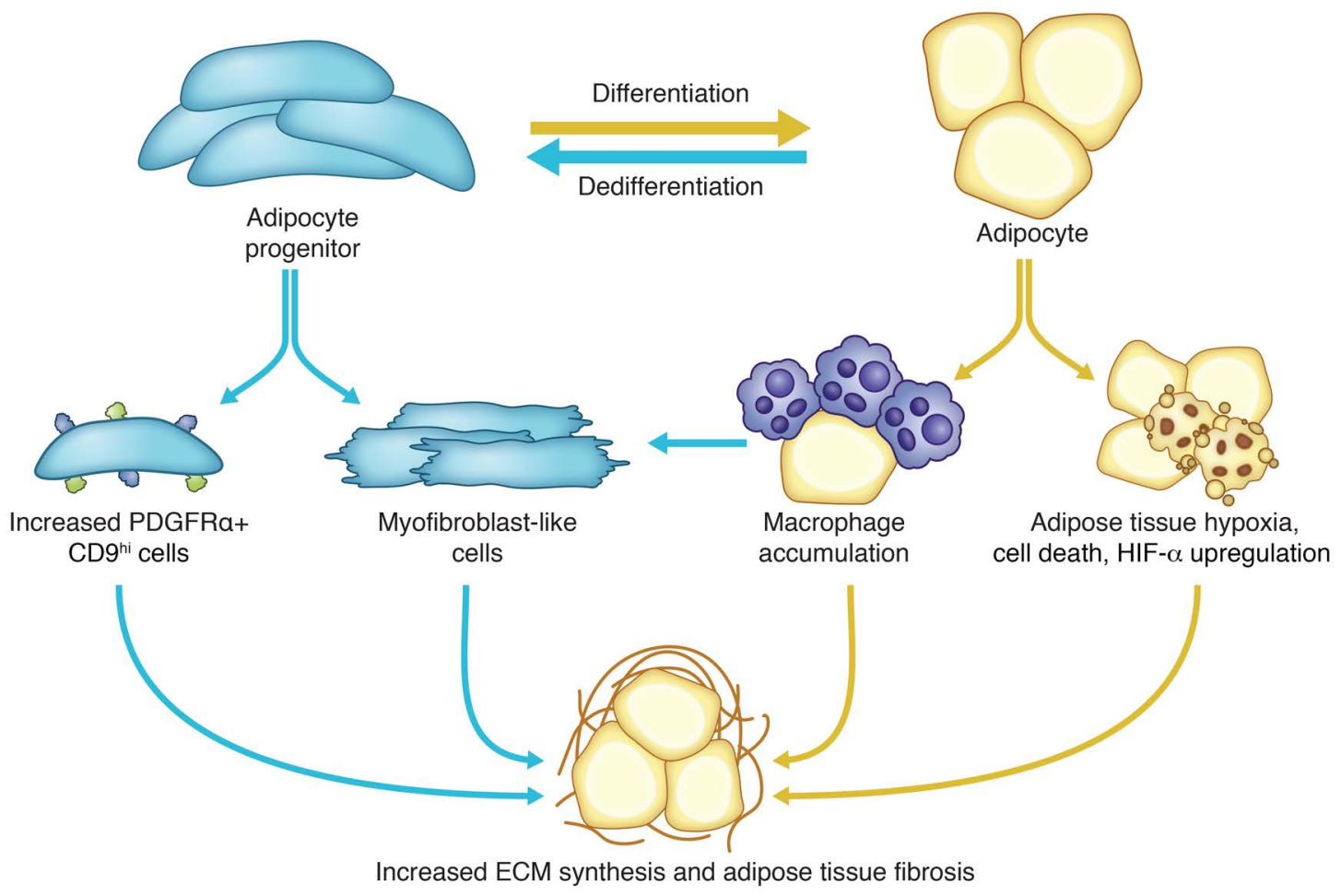

Figure 1. Schematic representation of the cellular events associated with increased collagen synthesis in obesity. The interplay among adipose tissue expansion, adipocyte differentiation, and adipose tissue fibrosis is marked by (a) dedifferentiation of adipocytes and increased production of fibrogenic progenitor cells, which lead to excess collagen synthesis in obese adipose tissue, and (b) growth of differentiated adipocytes during obesity by hypertrophy, which leads to inflammation and hypoxia, resulting in increased ECM production. Illustrated by Rachel Davidowitz.

significantly reduced triglyceride accumulation in adipocyte progenitors and impaired development of surrounding ECM. Interestingly, cells cultured on type V and VI collagen-coated dishes in the presence of this inhibitor partially recovered triglyceride accumulation. Inhibition of collagen synthesis also downregulated adipogenic gene expression in undifferentiated adipocyte progenitors (92), suggesting a direct role for type $\mathrm{V}$ and VI collagens in adipogenesis. These data suggest that collagens are necessary for triglyceride accumulation in adipocyte progenitors in the early stages of differentiation into mature adipocytes. However, type VI collagen-deficient $o b / o b$ mice have large adipocytes, suggesting type VI collagen limits adipocyte hypertrophy (29). It may be that collagens promote adipocyte triglyceride accumulation in the initial phases of adipocyte progenitor differentiation, but in the context of chronic high caloric intake, type VI collagen may limit the extent of mature adipocyte enlargement or may regulate adipocyte progenitor differentiation.

Matrix metalloproteinase (MMP) expression in adipose tissue and serum is significantly increased during obesity, suggesting these enzymes and their inhibitors (tissue inhibitors of metalloproteinases [TIMPs]) are involved in adipocyte differentiation $(87,88,93)$. Furthermore, elevated MMP expression correlates with expression of proinflammatory markers (94). In human subjects, BMI correlates with expression of gelatinases MMP-2 and MMP-9, both of which cleave denatured collagen $(93,95,96)$. Plasma MMP-9 levels also correlate with hyperlipidemia in humans (93). Latent MMP-9 remains bound to TIMP-1 before secretion $(97,98)$, and increased TIMP-1 plasma levels have been associated with obesity and hyperlipidemia in human patients $(93,99,100)$.

Increased MMP-2 and MMP-9 expression during adipocyte differentiation suggests that these enzymes may promote adipogenesis $(94,101)$. Consistent with this hypothesis, chemical MMP-2 inhibition in 3T3 adipocyte progenitors prevents differentiation in a dose-dependent manner (102). MMP-2 and MMP-9 can cleave type IV collagen in the basement membrane $(103,104)$. Interestingly, denatured but not native type IV collagen matrix induces adipogenic differentiation of cells of mesenchymal origin, supporting a proadipogenic role for these two MMPs (105).

MMP-2 is activated by MMP-14 (also known as membrane type 1 matrix metalloproteinase [MT1MMP]) at the cell surface $(106,107)$. Sillat et al. reported that MMP-2 or MMP-9, along with MMP-14 
Table 1. Roles of collagens and their regulators in obesity-associated metabolic dysfunction

\begin{tabular}{|c|c|c|c|}
\hline Collagens and their regulators & Probable role in obesity-related metabolism & Models studied & References \\
\hline Col-VIA & $\begin{array}{l}\text { Limits adipocyte growth during obesity; } \\
\text { associated with disrupted lipid homeostasis } \\
\text { Positive role in normal adipogenesis } \\
\text { Insulin resistance }\end{array}$ & $\begin{array}{l}\text { Col-VI-knockout }{ }^{A} \text { mice in } \\
\text { ob/ob background } \\
\text { Bovine intramuscular adipocyte } \\
\text { progenitors studied in vitro } \\
\text { Cells isolated from lean } \\
\text { and obese human subjects }\end{array}$ & $\begin{array}{c}29 \\
66 \\
169\end{array}$ \\
\hline Col-VA & Positive role in normal adipogenesis & $\begin{array}{l}\text { Bovine intramuscular adipocyte progenitors } \\
\text { studied in vitro }\end{array}$ & 66 \\
\hline Col-XVIIIA & $\begin{array}{l}\text { P2 promoter specific short-chain } \\
\text { product promotes adipocyte progenitor } \\
\text { differentiation and maintenance of } \\
\text { differentiated state }\end{array}$ & Col-XVIII promoter specific-nullA mice & 35 \\
\hline MMP-2 & Associated with adipocyte expansion & $\begin{array}{l}\text { Human visceral and subcutaneous } \\
\text { adipose tissue }\end{array}$ & 95,96 \\
\hline MMP-19 & Negative regulator of adipogenesis & MMP-19-null mice & 113 \\
\hline MMP-14 (MT1-MMP) & Positive regulator of adipogenesis & 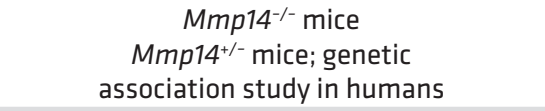 & $\begin{array}{l}110 \\
111\end{array}$ \\
\hline MMP-3 & Negative regulator of adipogenesis & MMP-3-null mice & 137 \\
\hline TIMP-1 & $\begin{array}{l}\text { Positive correlation with BMI } \\
\text { Regulates feeding behavior by acting } \\
\text { as downstream target of leptin in the } \\
\text { hypothalamus }\end{array}$ & $\begin{array}{l}\text { Human serum } \\
\text { TIMP-1-null mice }\end{array}$ & $\begin{array}{l}99 \\
89\end{array}$ \\
\hline
\end{tabular}

${ }^{A}$ Col, collagen type. ${ }^{B}$ LOX, lysyl oxidase.

and TIMP-2, forms ternary complexes that are important for basement membrane remodeling during adipogenesis (103). MMP-14 regulates type I collagen cleavage (108), and MMP-14-null mice develop soft tissue fibrosis, likely due to impaired collagen turnover (108). The complete loss of MMP-14 in these mice leads to postnatal lipodystrophy, a pathological condition in which the body is unable to produce fat (109). A genetic link between MMP14 haplotype 122(gcc) and phenotypic features of obesity, including increased BMI and waist/hip ratio and insulin resistance, was found in a cohort of Japanese patients (110), indicating a probable role for MMP-14 in the development of obesity. Compared to the Mmp14-1mice, $M m p 14^{+/-}$haploinsufficient mice are similar to WT animals, with respect to adipocyte mass, size, and adipogenic gene expression. Interestingly, $\mathrm{Mmp} \mathrm{4}^{+/-}$mice undergoing HFD challenge are unable to expand adipose tissue due to impaired type I collagen cleavage at the time of ECM remodeling during adipose tissue expansion (110). Moreover, in vitro experiments further validated an adipogenic role for MMP-14. Specifically, MMP-14 is not essential for adipogenesis in a two-dimensional culture system; however, interactions between MMP-14 and type I collagen in a 3D environment are necessary for adipocyte maturation (109). Additionally, transplantation of GFP-tagged, MMP-14-null stromal cells into inguinal fat pads of WT mice revealed that limited deposits of fat localize to the ectopic MMP-14-null cells after 14 days, emphasizing the adipogenic role of MMP-14 in a 3D environment. MMP-14-null mice 
also exhibit changes in adipogenesis at the epigenetic level that are recapitulated in cultured adipocytes; interestingly, epigenetic changes in adipogenesis upon MMP inhibition are rescued by treating cells with heat-denatured type I collagen $(111,112)$. Future studies are required to validate the effect of MMP-14mediated epigenetic regulation in an obesity model because it is unclear whether the adipogenic effect of MMP-14 occurs via signaling pathways that are independent of collagenolytic activity.

MMP-19 is also upregulated in adipose tissues during obesity $(87,88)$, and MMP-19-null mice have a marked body weight increase on HFD compared with WT control animals, suggesting an inhibitory role in adipogenesis (113), but the mechanisms remain unexplored.

Plasma MMP-8 levels correlate with obesity in adolescent populations $(114,115)$. Sca-I ${ }^{\text {hi }}$ mesenchymal stem cells in visceral adipose tissue show enriched MMP-8 and MMP-13 expression compared with similar cells from subcutaneous adipose tissue (116). Of note, visceral adipose tissue has greater adipogenic potential compared with subcutaneous adipose tissue (116). Because MMP-8 and MMP-13 are major collagenolytic enzymes (117-119), it is possible that increased expression may underlie the rapid and bulk collagenolysis observed in visceral adipose tissue compared with the relatively focal and slow collagenolysis in subcutaneous adipose tissue (116). MMP-8 and MMP-13 expression may therefore be an important determinant of fat depot specificity $(116,120)$.

Knocking down of MMP-13 in 3T3-L1 adipocyte progenitors inhibits differentiation, thereby reducing adipogenesis. Treatment of HFD-fed mice with MMP-13-specific chemical inhibitor 4-[4-(4-fluorophenoxy)-benzenesulfonyl amino] tetrahydropyran-4-carboxylic acid (CP-544439) (121) results in greater type I collagen expression and adipose tissue fibrosis. CP-544439-treated mice also have reduced expression of the key adipogenesis regulator PPAR $\gamma(120,122-124)$. The antifibrotic effects of PPAR family proteins have been described in different tissue systems (125-130). MMP-13-mediated regulation of PPAR expression in obese adipose tissue might therefore act as an important molecular switch that determines fibrogenic or adipogenic adipocyte progenitor fate. PPAR proteins seem to mediate antifibrotic effects via inhibition of TGF- $\beta$ signaling $(125,128,130)$. Conversely, canonical and noncanonical downstream mediators of TGF- $\beta$ are important transcriptional regulators of different MMPs (131-134), suggesting a feedback loop that modulates the balance between fibrosis and adipogenesis. Moreover, TGF- $\beta$ expression positively correlates with the expression of different MMP inhibitors, including TIMP-1, TIMP-3, and TIMP-4; therefore, MMP activity in omental adipose tissue should be decreased in morbidly obese human subjects (135).

MMP-3-deficient mice have accelerated adipogenesis in the mammary gland, highlighting the inhibitory effect of MMP-3 on adipocyte differentiation (136). An antagonistic role for MMP-3 and TIMP-4 in adipocyte differentiation has been reported (137). In primary human adipocytes, MMP-3 overexpression inhibits differentiation, while recombinant TIMP-4 promotes adipogenesis. Increased MMP-3 expression and enzyme activity have been observed in HFD-fed male mice; thus TIMP-4 (137), via MMP-3 inhibition, may influence whether adipocytes undergo hypertrophy or hyperplasia. Recently, Timp4-knockout mice were shown to be protected from HFD-induced obesity, with reduced adipocyte hypertrophy and fibrosis (90).

A disintegrin and a metalloprotease domain with thrombospondin motifs (ADAMTS) matrix-associated metalloprotease family proteins have also been implicated in adipocyte lineage commitment (138). In mice, injection of ADAMTS-targeting, shRNA-expressing adenovirus into inguinal fat pads leads to adipocyte hypertrophy, insulin resistance, increased plasma cholesterol, and increased LDL-cholesterol (138). Moreover, ADAMTS-1-encoding mRNA is decreased in adipose tissue of obese human patients and inversely correlates with BMI (138-140). Blocking ADAMTS-1 proteolytic activity by site-directed mutagenesis reverses the inhibitory effect on the expression of adipocyte progenitor marker PREF-1 and restores adipogenesis (138). Therefore, ECM-modifying enzymes outside the traditional MMP family also contribute to adipocyte differentiation.

\section{Evidence for adipose tissue fibrosis in regulating metabolic homeostasis}

Adipose tissue fibrosis has multiple potential effects on adipocytes. By providing a rigid ECM, fibrosis may prevent excessive enlargement of adipocytes. Fibrosis may exert shear stress on the adipocyte membrane, opposing the mechanical stress exerted by enlarged lipid droplets within the cell. Adipose tissue fibrosis may also activate signaling events secondary to ECM ligands in fibrotic tissue-binding cell surface receptors (141). Whether adipose tissue fibrosis is beneficial or deleterious with respect to metabolic homeostasis is debatable, with studies supporting both possibilities (Figure 2). 


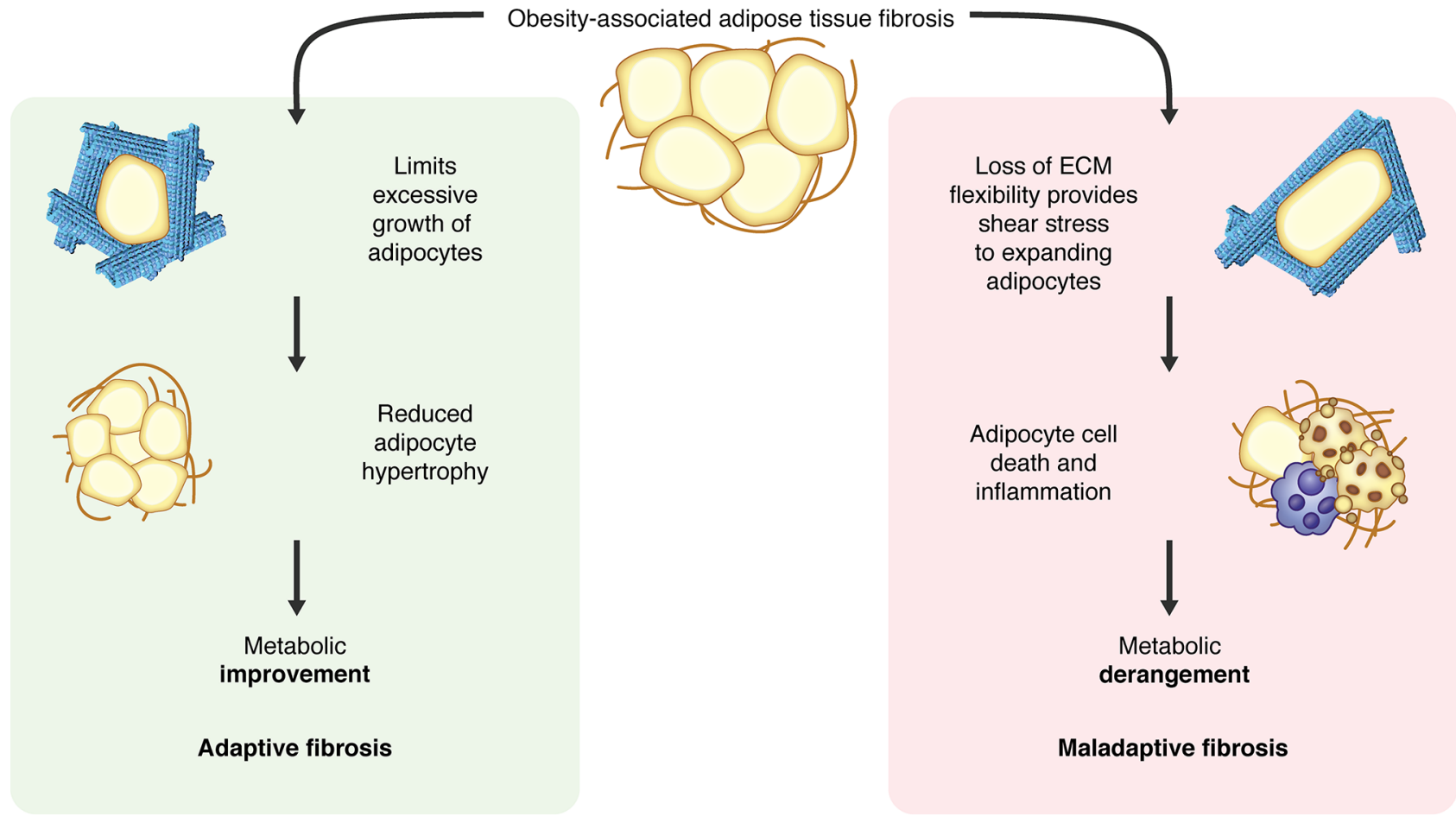

Figure 2. The metabolic outcomes of obesity-associated adipose tissue fibrosis are controversial. Excess collagen deposition may reduce adipocyte hypertrophy and consequently preserve adipocyte function. On the other hand, rigid matrix may exert shear stress on expanding adipocytes, leading to adipocyte cell death and consequent inflammation. These two possibilities are proposed to have countervailing effects on metabolic outcomes. Illustrated by Rachel Davidowitz.

Human studies. In human patients, fibrosis of omental adipose tissue, but not subcutaneous adipose tissue, negatively correlates with blood triglyceride levels and positively correlates with HDL-cholesterol levels (19). Furthermore, omental fibrosis inversely correlates with omental adipocyte size in obese human patients (19). Decreased omental adipose tissue fibrosis and greater adipocyte hypertrophy are associated with worse metabolic profiles in obese diabetic patients compared with those without diabetes (142). Moreover, obese patients with smaller omental adipocytes have healthier lipid profiles (14). In South Asian Indian populations, omental adipocyte size correlates more strongly with measures of adiposity and metabolic dysfunction than subcutaneous adipocyte size (143), further supporting a link between omental adipocyte size and metabolic outcome in humans. Decreased tensile strength is also a surrogate for less severe fibrosis in the omental adipose tissue of metabolically unhealthy obese human subjects compared with healthy obese subjects, leading to the hypothesis that fibrosis limits adipocyte hypertrophy, which may in turn preserve adipocyte function (144). Together, these data suggest that omental fibrosis can be an adaptive phenomenon that may be beneficial for metabolism by limiting adipocyte size. However, a recent study comparing highly insulin-resistant with less insulin-resistant severely obese human subjects failed to find any correlation between omental adipocyte size and fibrosis (145). Moreover, this study showed an inverse correlation between insulin sensitivity and omental tissue fibrosis. A recent report also suggested that pericellular collagen accumulation, especially in omental adipose tissue, correlates with total adiposity and cardiometabolic risk in lean to moderately obese women (146). Lawler et al. showed that obese, insulin-resistant human subjects with a similar BMI have increased subcutaneous adipose tissue fibrosis compared with obese, insulin-sensitive human subjects, corresponding to the increased subcutaneous adipose tissue stiffness observed in diabetic patients (147). These studies suggest a maladaptive role for subcutaneous adipose tissue fibrosis in obesity-associated metabolic dysregulation (148).

Murine studies. Conflicting phenotypes have been reported in humans and mouse models. Alcalá et al. have shown that in HFD-fed mice vitamin E supplementation reduces visceral adipose tissue fibrosis, enlarges adipocyte size, and is associated with improved metabolic profiles (149). Reduced subcutaneous adipose tissue fibrosis by antibody-mediated neutralization of endotrophin (the cleaved product of type VI collagen) in HFD-fed mice is associated with improved insulin sensitivity, supporting a potentially maladaptive role for fibrosis in the development of obesity (16). 
Important and potentially confounding factors to consider are whether adipocyte expansion in obesity occurs through hyperplasia or hypertrophy and how fibrosis regulates these etiologically different processes that may in turn regulate fibrosis. Hyperplasia-mediated adipocyte expansion is associated with a metabolically healthy obese state $(9,150)$, whereas hypertrophic expansion and accompanying adipose tissue fibrosis are linked with metabolically dysfunctional adipose tissue $(11,141,151)$. These data suggest that addition of new adipocytes to accommodate excess lipid stores is a beneficial adaptation. Conversely, enlargement of established adipocytes may ultimately lead to deleterious effects due to adipocyte necrosis and subsequent inflammation (152).

Potential pitfalls and challenges in studying adipose tissue fibrosis. We believe that fat depot-specific variations represent a major source of confounding reports in the literature. In early stages of HFD exposure, both subcutaneous and visceral fat pads respond by adipocyte hypertrophy (153); however, in response to ongoing HFD exposure, visceral fat pads are more likely to undergo hyperplasia for expansion, while subcutaneous fat pads primarily expand through adipocyte hypertrophy (153). Even among the visceral fat pads, mesenteric, perigonadal, and retroperitoneal fat pads differ significantly in terms of physiology. A large percentage of visceral fat is stored in the mesenteric/omental fat depot in humans, while the visceral fat depot in mice is mostly perigonadal (154). The time frame of epididymal or perigonadal adipose tissue development is different from that of subcutaneous fat pads, suggesting that these fat pads may arise from two different progenitor cells (153).

Other differences between humans and mice confound the literature as well. There are fundamental differences between human and murine subjects, with respect to not only fat pad distribution but also matrix-specific gene expression within a given fat pad. McCulloch et al., in 2015, reported higher type VI collagen expression in the stromal vascular fraction of tissue (155), which includes adipocyte progenitors, and higher subcutaneous adipocytes compared with omental and visceral fat in humans (155). In contrast, mouse adipose compartments exhibit a global and uniform increase of type VI collagen expression (29). Additionally, obesity tends to develop gradually in humans, while fat mass gain is rapid and massive in experimental mouse models. For example, long-term overfeeding in human twins caused an approximately $10 \%$ weight gain over a 14 -week period compared with mouse models, where body weight doubles during a similar time frame $(17,156)$. The extent to which such rapid weight gain influences ECM biology in murine subjects compared with humans is not known. In addition, there may be genetic predispositions to developing fibrosis in obese individuals, although no potential genetic links to fibrosis have been discovered by GWAS (157). The gut microbiome may also exert an effect on these processes $(158,159)$.

Differences among studies may also be due to the methods used to quantify collagen accumulation in adipose tissues. Recent studies suggest that pericellular collagen deposition and distribution rather than total collagen content in adipose tissue correlate to the metabolic outcome $(146,160)$. Different methodological approaches to evaluating fibrosis, such as measuring collagen mRNA expression, measuring total collagen protein content by hydroxyproline or Sircol assay, or staining of pericellular collagen to assess the distribution of collagen, may significantly alter interpretations offered in individual studies.

\section{Type VI collagen and endotrophin in the regulation of adipocyte function}

Although type VI collagen constitutes a very small amount of the total collagen network, deletion of the type VI collagen gene can alter adipocyte hypertrophy and the metabolic outcome of obesity without affecting the fibrotic status of the tissue. Data from mice with genetic deletion of type VI collagen (29) are consistent with human studies linking increased type VI collagen expression in obesity with poor metabolic outcomes $(29,51,148)$. Type VI collagen deficiency in $o b / o b$ mice improves systemic lipid profiles, increases glucose clearance after oral glucose administration, reduces body weight, decreases adipocyte necrosis, and reduces inflammation. Compared with $o b / o b$ mice, collagen VI-deficient $o b / o b$ mice have reduced food intake and altered respiratory exchange ratios, consistent with a shift toward fatty acid usage and away from carbohydrates as a fuel source. These metabolic improvements are associated with a significant increase in adipocyte size and are in stark contrast with human studies, which show a correlation between reduced adipocyte size and improved serum lipid profiles (14). Moreover, there is no difference in the extent of fibrosis in adipose tissue, as measured by hydroxyproline assay or Picrosirius staining of tissues from collagen VI-deficient $o b / o b$ mice (29).

Knocking down of type VI collagen results in differential expression of multiple genes relevant for adipocyte homeostasis and ECM, including lumican, decorin, elastin, TGFB, MMPs, and PPARG (29). One 
possibility is that the reduced expression of matrix organizational proteins in collagen VI-deficient $o b / o b$ mice may relieve the expanding adipocytes from shear stress, leading to decreased necrosis, decreased release of adipokines, and improved metabolic function. Alternatively, the beneficial effects of type VI collagen deletion on the metabolic profile may result from altered signaling with the loss of this matrix protein.

Endotrophin, the cleavage product from the C5 domains of the collagen VI $\alpha 3$ chain, has a role in obesity and mammary tumor growth $(16,161)$. Endotrophin is enriched in obese adipose ECM (16), and endotrophin overexpression in adipose tissue aggravates HFD-induced fibrosis and metabolic derangements. Antibody-mediated endotrophin neutralization in HFD-challenged WT mice rescues abnormal metabolic profiles without altering adipocyte size (16). Moreover, endotrophin-depleted, HFD-fed mice have no significant body weight loss. Endotrophin neutralization also markedly decreases subcutaneous WAT fibrosis and reduces inflammation in both epididymal and subcutaneous adipose tissues. However, the causal relationship between these processes with respect to metabolic parameters remains ambiguous. One unifying hypothesis might be that increased collagen VI production leads to both fibrosis and endotrophin accumulation, with fibrosis limiting adipocyte size and endotrophin mediating the negative metabolic consequences of obesity. Specific proteases that regulate posttranslational endotrophin processing have yet to be identified. Furthermore, endotrophin-specific receptors that promote signaling events (162) and downstream effects are largely unknown. In a preliminary study, Rodriguez et al. proposed that integrin receptors may mediate the effects of type VI collagen and endotrophin in skeletal muscle glucose homeostasis (163).

\section{Potential links between inflammation and fibrosis in obesity}

The relationship between inflammation and fibrosis is complex, and although inflammation can lead to fibrosis, fibrosis can occur independent of inflammation. We address the interplay between inflammation and fibrosis in obesity in this section. The contribution of macrophages and other immune cells, such as different $\mathrm{B}$ and $\mathrm{T}$ cell subtypes, remains a matter of debate. Inflammatory cell profiles in adipose tissue have been extensively studied $(123,164-167)$ and are beyond the scope of this Review. We will focus on the understanding of the role of inflammation in the regulation of fibrosis in obese adipose tissue.

Role of TGF- $\beta$ in adipose tissue fibrosis. TGF- $\beta$ is a master regulator and promoter of fibrosis in multiple tissues, including adipose tissue (168). Isolated adipocytes treated with TGF- $\beta$ show increased expression of ECM remodeling proteins, and TGF- $\beta$ activation has been correlated with increased expression of basement membrane components in obese adipose tissue (52). Coculture of adipocytes with macrophages increases TGF- $\beta$ activation and subsequent phosphorylation of SMADs, leading to a significant increase in the production of type VI collagen and other ECM components (169). In one particular study, human PDGFR $\alpha^{+}$cells isolated from lean individuals showed a profibrotic phenotype when treated with TGF- $\beta$ (71), and TGF- $\beta$ and PDGF ligands have been reported to be synergistic in promoting fibrosis. TGF- $\beta$ can also be antiinflammatory and promote M2-like macrophage polarization $(170,171)$. Interestingly, M2 macrophages, which exhibit elevated TGF- $\beta$ secretion and an antiinflammatory profile, localize to fibrotic areas of adipose tissue $(169,172)$. These data contrast with those describing the relative preponderance of M1 macrophages in obesity-associated adipose inflammation (173). Importantly, temporal changes in TGF- $\beta$ activity during the development of obesity have not been elucidated.

Temporal patterns of inflammation and fibrosis during obesity. The assumption that inflammation drives the fibrotic process may not be entirely correct. A detailed time course analysis of the first 20 days of HFD challenge in a mouse model showed the appearance of fibrotic streaks in the adipose compartment before formation of the characteristic inflammatory signature and macrophage crown-like structures surrounding adipocytes (78). Fibrotic gene expression increased 2-4 days after initiating a HFD, whereas expression of proinflammatory genes, such as Tnfa, coincided with the presence of crown-like structures at days 13-15. These data indicate that fibrosis may in fact precede inflammation, thereby limiting adipocyte growth in obese individuals $(71,78)$, and therefore, might not be a direct sequela of inflammatory cell infiltration. Further studies to characterize temporal changes in macrophage phenotypes and their role in amplifying the fibrotic response are needed. Recent studies also challenge the concept of hypoxia-induced inflammation in obese adipose tissue, because hyperoxia is also associated with inflammation $(81,82)$. It is therefore necessary to understand the temporal changes in oxygen tension in adipose tissue during the development of obesity. It is likely that temporal patterns of hypoxia and hyperoxia activate unique sets of inflammatory responses that may affect the fibrotic response differently. 


\section{Chronic High Caloric Intake}

$\begin{gathered}\text { Larly Stage of } \\ \text { Obesity }\end{gathered}$
$\begin{gathered}\text { Adipocyte } \\ \text { growth } \\ \text { adipocytes }\end{gathered} \longrightarrow$ Adipocyte hypertrophy,
hypoxia, cell death

Figure 3. Temporal changes that take place in the adipose compartment with chronic high caloric intake. Adipose tissue expansion, adipose tissue fibrosis, and inflammation in obesity may lead to adverse metabolic consequences over time through multiple mechanisms. Studies of temporal progression of these features suggest that fibrosis may precede inflammation that is associated with adverse metabolic consequences. Illustrated by Rachel Davidowitz.

Direct role of ECM in adipose tissue inflammation. The observation that fibrosis occurs before inflammation raises the question of whether the ECM itself affects inflammation. To evaluate the direct role of adipose tissue ECM on the inflammatory profile of adipocytes, Pellegrinelli et al. (174) developed a 3D culture system that uses human adipocytes conditioned with decellularized materials of subcutaneous adipose tissue (dMAT). Adipokine secretion and lipolysis decreased while certain cytokines and fibrotic mediators increased in cells treated with obese subjects' dMAT, suggesting a direct effect of ECM on fibroinflammatory signaling in adipocytes. No studies to date have compared the effect of dMAT from metabolically unhealthy obese samples to that of metabolically healthy obese samples. Moreover, these findings need to be further validated in adipocytes conditioned with dMAT from visceral fat depots because subcutaneous fat is not directly correlated with the systemic metabolic profile $(19,154,175)$. Obesity-associated temporal changes in fibrosis and inflammation are depicted in Figure 3.

\section{Integrins: the functional link between matrix and cell metabolism}

In general, the biology of integrins in tissue fibrosis has been extensively characterized, but the role of individual integrins in adipose fibrosis and obesity is relatively understudied (176). A limited number of studies have explored this facet of integrins. For example, Pellegrinelli et al. proposed that adipocyte mechanotransduction is at least partially mediated by $\beta_{1}$ integrins (174). Other evidence linking integrins to adipose tissue fibrosis comes from studies of the integrin ligand osteopontin, knockout of which protects mice from both obesity and fibrosis (177). More work has been done on the influence of integrins on adipogenic differentiation, including $\alpha \mathrm{v}$ (176) and $\alpha_{5}(178)$. Recently, $\alpha_{5}$ integrin subunit has been identified as a surface marker for fibrogenic progenitor cells in obese adipose tissue of mice (179). Further details on the role of integrins in adipose tissue biology and metabolism in general (not relating to fibrosis) have been described (180-185) but are beyond the scope of this Review.

\section{Future directions: therapeutic perspective}

This Review has highlighted knowledge gaps in the understanding of the interplay between adipocyte biology and ECM in obesity. The influence of ECM and its constituents on metabolic parameters and vice 
versa in the obese state remain incompletely understood. For example, type VI collagen appears deleterious, whereas other collagens appear protective, at least initially, in the development of obesity-associated complications. Deconvolution of the relationships among ECM deposition, local and systemic inflammation, adipocyte differentiation, adipocyte size, and metabolic dysregulation in the obese state is clearly needed. Future studies should address how adipose tissue ECM relates to obesity-associated endocrine and neurohormonal changes and vice versa. Until all these interrelated relationships are more clearly understood and can explain observations in humans and mice, attempts to target specific pathways, signaling molecules, or cell types may remain empiric to some extent. Yet, there is enough evidence and clearly an unmet clinical and public health need for attempting to address the development and progression of the unhealthy obese state. Modulation of matrix remodeling enzymes, inhibitors, and signaling molecules that mediate cellmatrix interactions are especially promising pharmacological targets. How cells degrade matrix in the adipose compartment and whether cell-based matrix remodeling can be targeted to improve obesity-associated comorbidities are unexplored areas. In sum, the influence of ECM on adipose tissue biology is extensive and is a ripe area both for mechanistic investigative research and for therapeutic drug development.

\section{Acknowledgments}

We thank I. Lahortiga and L. Cox for providing Library of Science and medical illustrations. This work was supported by awards from the US NIH (HL136377-01 and DK110098) to K. Atabai.

Address correspondence to: Kamran Atabai, Box 3118, 555 Mission Bay Blvd. S., University of California San Francisco, San Francisco, California, 94158, USA. Phone: 415.514.1159; Email: Kamran.Atabai@ucsf.edu.

1. Després JP. Abdominal obesity as important component of insulin-resistance syndrome. Nutrition. 1993;9(5):452-459.

2. Hotamisligil GS, Shargill NS, Spiegelman BM. Adipose expression of tumor necrosis factor-alpha: direct role in obesity-linked insulin resistance. Science. 1993;259(5091):87-91.

3. Steinberg HO, Chaker H, Leaming R, Johnson A, Brechtel G, Baron AD. Obesity/insulin resistance is associated with endothelial dysfunction. Implications for the syndrome of insulin resistance. J Clin Invest. 1996;97(11):2601-2610.

4. Tchernof A, et al. The dense LDL phenotype. The dense LDL phenotype. Association with plasma lipoprotein levels, visceral obesity, and hyperinsulinemia in men. Diabetes Care. 1996;19(6):629-637.

5. Vohl MC, et al. The apoB-100 gene EcoRI polymorphism influences the relationship between features of the insulin resistance syndrome and the hyper-apoB and dense LDL phenotype in men. Diabetes. 1996;45(10):1405-1411.

6. Hollister LE, Overall JE, Snow HL. Relationship of obesity to serum triglyceride, cholesterol, and uric acid, and to plasma-glucose levels. Am J Clin Nutr. 1967;20(7):777-782.

7. Adams JM, et al. Ceramide content is increased in skeletal muscle from obese insulin-resistant humans. Diabetes. 2004;53(1):25-31.

8. Jo J, et al. Hypertrophy and/or hyperplasia: dynamics of adipose tissue growth. PLoS Comput Biol. 2009;5(3):e1000324

9. Kim JY, et al. Obesity-associated improvements in metabolic profile through expansion of adipose tissue. J Clin Invest. 2007;117(9):2621-2637.

10. Sun K, Kusminski CM, Scherer PE. Adipose tissue remodeling and obesity. J Clin Invest. 2011;121(6):2094-2101.

11. Rutkowski JM, Stern JH, Scherer PE. The cell biology of fat expansion. J Cell Biol. 2015;208(5):501-512.

12. Scherer PE. The Multifaceted Roles of Adipose Tissue-Therapeutic Targets for Diabetes and Beyond: The 2015 Banting Lecture. Diabetes. 2016;65(6):1452-1461.

13. Drolet R, et al. Hypertrophy and hyperplasia of abdominal adipose tissues in women. Int J Obes (Lond). 2008;32(2):283-291.

14. Arner E, et al. Adipocyte turnover: relevance to human adipose tissue morphology. Diabetes. 2010;59(1):105-109.

15. Johnson PR, Hirsch J. Cellularity of adipose depots in six strains of genetically obese mice. J Lipid Res. 1972;13(1):2-11.

16. Sun K, et al. Endotrophin triggers adipose tissue fibrosis and metabolic dysfunction. Nat Commun. 2014;5:3485.

17. Strissel KJ, et al. Adipocyte death, adipose tissue remodeling, and obesity complications. Diabetes. 2007;56(12):2910-2918

18. Mariman EC, Wang P. Adipocyte extracellular matrix composition, dynamics and role in obesity. Cell Mol Life Sci. 2010;67(8):1277-1292.

19. Divoux A, et al. Fibrosis in human adipose tissue: composition, distribution, and link with lipid metabolism and fat mass loss Diabetes. 2010;59(11):2817-2825.

20. Mori S, Kiuchi S, Ouchi A, Hase T, Murase T. Characteristic expression of extracellular matrix in subcutaneous adipose tissue development and adipogenesis; comparison with visceral adipose tissue. Int J Biol Sci. 2014;10(8):825-833.

21. Lee YJ, et al. Nuclear receptor PPAR $\gamma$-regulated monoacylglycerol O-acyltransferase 1 (MGAT1) expression is responsible for the lipid accumulation in diet-induced hepatic steatosis. Proc Natl Acad Sci U S A. 2012;109(34):13656-13661.

22. Wang P, Bouwman FG, Mariman EC. Generally detected proteins in comparative proteomics — a matter of cellular stress response? Proteomics. 2009;9(11):2955-2966.

23. Adachi J, Kumar C, Zhang Y, Mann M. In-depth analysis of the adipocyte proteome by mass spectrometry and bioinformatics. Mol Cell Proteomics. 2007;6(7):1257-1273.

24. Lim JM, Sherling D, Teo CF, Hausman DB, Lin D, Wells L. Defining the regulated secreted proteome of rodent adipocytes upon the induction of insulin resistance. J Proteome Res. 2008;7(3):1251-1263.

25. Alvarez-Llamas G, et al. Characterization of the human visceral adipose tissue secretome. Mol Cell Proteomics. 2007;6(4):589-600. 
26. Kratchmarova I, et al. A proteomic approach for identification of secreted proteins during the differentiation of 3T3-L1 preadipocytes to adipocytes. Mol Cell Proteomics. 2002;1(3):213-222.

27. Molina $\mathrm{H}$, et al. Temporal profiling of the adipocyte proteome during differentiation using a five-plex SILAC based strategy. J Proteome Res. 2009;8(1):48-58.

28. Chen X, Cushman SW, Pannell LK, Hess S. Quantitative proteomic analysis of the secretory proteins from rat adipose cells using a 2D liquid chromatography-MS/MS approach. J Proteome Res. 2005;4(2):570-577.

29. Khan T, et al. Metabolic dysregulation and adipose tissue fibrosis: role of collagen VI. Mol Cell Biol. 2009;29(6):1575-1591.

30. Pierleoni C, Verdenelli F, Castellucci M, Cinti S. Fibronectins and basal lamina molecules expression in human subcutaneous white adipose tissue. Eur J Histochem. 1998;42(3):183-188.

31. Timpl R, Wiedemann H, van Delden V, Furthmayr H, Kühn K. A network model for the organization of type IV collagen molecules in basement membranes. Eur J Biochem. 1981;120(2):203-211.

32. Kühn K, et al. Macromolecular structure of basement membrane collagens. FEBS Lett. 1981;125(1):123-128.

33. Sun K, Tordjman J, Clément K, Scherer PE. Fibrosis and adipose tissue dysfunction. Cell Metab. 2013;18(4):470-477.

34. Dong S, Cole GJ, Halfter W. Expression of collagen XVIII and localization of its glycosaminoglycan attachment sites. J Biol Chem. 2003;278(3):1700-1707.

35. Aikio M, et al. Specific collagen XVIII isoforms promote adipose tissue accrual via mechanisms determining adipocyte number and affect fat deposition. Proc Natl Acad Sci U S A. 2014;111(30):E3043-E3052.

36. Bonaldo P, Russo V, Bucciotti F, Doliana R, Colombatti A. Structural and functional features of the alpha 3 chain indicate a bridging role for chicken collagen VI in connective tissues. Biochemistry. 1990;29(5):1245-1254.

37. Brown JC, Golbik R, Mann K, Timpl R. Structure and stability of the triple-helical domains of human collagen XIV. Matrix Biol. 1994;14(4):287-295.

38. Kuo HJ, Maslen CL, Keene DR, Glanville RW. Type VI collagen anchors endothelial basement membranes by interacting with type IV collagen. J Biol Chem. 1997;272(42):26522-26529.

39. Sabatelli P, et al. Collagen VI deficiency affects the organization of fibronectin in the extracellular matrix of cultured fibroblasts. Matrix Biol. 2001;20(7):475-486.

40. Sasaki T, Göhring W, Pan TC, Chu ML, Timpl R. Binding of mouse and human fibulin-2 to extracellular matrix ligands. J Mol Biol. 1995;254(5):892-899.

41. Takahashi T, Cho HI, Kublin CL, Cintron C. Keratan sulfate and dermatan sulfate proteoglycans associate with type VI collagen in fetal rabbit cornea. J Histochem Cytochem. 1993;41(10):1447-1457.

42. Wiberg C, et al. Biglycan and decorin bind close to the n-terminal region of the collagen VI triple helix. J Biol Chem. 2001;276(22):18947-18952.

43. Specks $\mathrm{U}$, et al. Structure of recombinant $\mathrm{N}$-terminal globule of type VI collagen alpha 3 chain and its binding to heparin and hyaluronan. EMBO J. 1992;11(12):4281-4290.

44. Cescon M, Gattazzo F, Chen P, Bonaldo P. Collagen VI at a glance. J Cell Sci. 2015;128(19):3525-3531.

45. Bidanset DJ, Guidry C, Rosenberg LC, Choi HU, Timpl R, Hook M. Binding of the proteoglycan decorin to collagen type VI. J Biol Chem. 1992;267(8):5250-5256.

46. Doane KJ, Howell SJ, Birk DE. Identification and functional characterization of two type VI collagen receptors, alpha 3 beta 1 integrin and NG2, during avian corneal stromal development. Invest Ophthalmol Vis Sci. 1998;39(2):263-275.

47. Pfaff M, Aumailley M, Specks U, Knolle J, Zerwes HG, Timpl R. Integrin and Arg-Gly-Asp dependence of cell adhesion to the native and unfolded triple helix of collagen type VI. Exp Cell Res. 1993;206(1):167-176

48. Tulla M, et al. Selective binding of collagen subtypes by integrin alpha 1I, alpha 2I, and alpha 10I domains. J Biol Chem. 2001;276(51):48206-48212.

49. Chen P, Cescon M, Megighian A, Bonaldo P. Collagen VI regulates peripheral nerve myelination and function. FASEB J. 2014;28(3):1145-1156.

50. Chen P, Cescon M, Bonaldo P. Lack of Collagen VI Promotes Wound-Induced Hair Growth. J Invest Dermatol. 2015;135(10):2358-2367.

51. Pasarica M, et al. Adipose tissue collagen VI in obesity. J Clin Endocrinol Metab. 2009;94(12):5155-5162.

52. Reggio $S$, et al. Increased basement membrane components in adipose tissue during obesity: links with TGF $\beta$ and metabolic phenotypes. J Clin Endocrinol Metab. 2016;101(6):2578-2587.

53. Henegar C, et al. Adipose tissue transcriptomic signature highlights the pathological relevance of extracellular matrix in human obesity. Genome Biol. 2008;9(1):R14.

54. Nie J, Sage EH. SPARC inhibits adipogenesis by its enhancement of beta-catenin signaling. J Biol Chem. 2009;284(2):1279-1290.

55. Bradshaw AD, Graves DC, Motamed K, Sage EH. SPARC-null mice exhibit increased adiposity without significant differences in overall body weight. Proc Natl Acad Sci U S A. 2003;100(10):6045-6050.

56. Kim J, et al. Enhanced biglycan gene expression in the adipose tissues of obese women and its association with obesity-related genes and metabolic parameters. Sci Rep. 2016;6:30609.

57. Wang P, Keijer J, Bunschoten A, Bouwman F, Renes J, Mariman E. Insulin modulates the secretion of proteins from mature 3T3-L1 adipocytes: a role for transcriptional regulation of processing. Diabetologia. 2006;49(10):2453-2462.

58. Wilsie LC, Chanchani S, Navaratna D, Orlando RA. Cell surface heparan sulfate proteoglycans contribute to intracellular lipid accumulation in adipocytes. Lipids Health Dis. 2005;4:2.

59. Voros G, Sandy JD, Collen D, Lijnen HR. Expression of aggrecan(ases) during murine preadipocyte differentiation and adipose tissue development. Biochim Biophys Acta. 2006;1760(12):1837-1844

60. Aratani Y, Kitagawa Y. Enhanced synthesis and secretion of type IV collagen and entactin during adipose conversion of 3T3-L1 cells and production of unorthodox laminin complex. J Biol Chem. 1988;263(31):16163-16169.

61. Vaicik MK, et al. Laminin $\alpha 4$ deficient mice exhibit decreased capacity for adipose tissue expansion and weight gain. PLoS One. 2014;9(10):e109854.

62. Yao Y, Norris EH, Mason CE, Strickland S. Laminin regulates PDGFR $\beta(+)$ cell stemness and muscle development. Nat Commun. 2016;7:11415. 
63. Pastel E, Joshi S, Knight B, Liversedge N, Ward R, Kos K. Effects of Exendin-4 on human adipose tissue inflammation and ECM remodelling. Nutr Diabetes. 2016;6(12):e235.

64. Wang A, et al. Exendin-4 Upregulates adiponectin level in adipocytes via Sirt1/Foxo-1 signaling pathway. PLoS One. 2017;12(1):e0169469.

65. Kubo Y, Kaidzu S, Nakajima I, Takenouchi K, Nakamura F. Organization of extracellular matrix components during differentiation of adipocytes in long-term culture. In Vitro Cell Dev Biol Anim. 2000;36(1):38-44.

66. Nakajima I, Muroya S, Tanabe R, Chikuni K. Positive effect of collagen V and VI on triglyceride accumulation during differentiation in cultures of bovine intramuscular adipocytes. Differentiation. 2002;70(2-3):84-91.

67. Weiner FR, Shah A, Smith PJ, Rubin CS, Zern MA. Regulation of collagen gene expression in 3T3-L1 cells. Effects of adipocyte differentiation and tumor necrosis factor alpha. Biochemistry. 1989;28(9):4094-4099.

68. Tam CS, Tordjman J, Divoux A, Baur LA, Clément K. Adipose tissue remodeling in children: the link between collagen deposition and age-related adipocyte growth. J Clin Endocrinol Metab. 2012;97(4):1320-1327.

69. Keophiphath M, Achard V, Henegar C, Rouault C, Clément K, Lacasa D. Macrophage-secreted factors promote a profibrotic phenotype in human preadipocytes. Mol Endocrinol. 2009;23(1):11-24.

70. Lacasa D, Taleb S, Keophiphath M, Miranville A, Clement K. Macrophage-secreted factors impair human adipogenesis: involvement of proinflammatory state in preadipocytes. Endocrinology. 2007;148(2):868-877.

71. Marcelin G, et al. A PDGFR $\alpha$-mediated switch toward CD9high adipocyte progenitors controls obesity-induced adipose tissue fibrosis. Cell Metab. 2017;25(3):673-685.

72. Olson LE, Soriano P. Increased PDGFRalpha activation disrupts connective tissue development and drives systemic fibrosis. Dev Cell. 2009;16(2):303-313.

73. Kuhn C, McDonald JA. The roles of the myofibroblast in idiopathic pulmonary fibrosis. Ultrastructural and immunohistochemical features of sites of active extracellular matrix synthesis. Am J Pathol. 1991;138(5):1257-1265.

74. Moore-Morris T, et al. Resident fibroblast lineages mediate pressure overload-induced cardiac fibrosis. J Clin Invest. 2014;124(7):2921-2934.

75. Knittel T, et al. Rat liver myofibroblasts and hepatic stellate cells: different cell populations of the fibroblast lineage with fibrogenic potential. Gastroenterology. 1999;117(5):1205-1221.

76. Martins V, Gonzalez De Los Santos F, Wu Z, Capelozzi V, Phan SH, Liu T. FIZZ1-induced myofibroblast transdifferentiation from adipocytes and its potential role in dermal fibrosis and lipoatrophy. Am J Pathol. 2015;185(10):2768-2776.

77. Lessard J, et al. Characterization of dedifferentiating human mature adipocytes from the visceral and subcutaneous fat compartments: fibroblast-activation protein alpha and dipeptidyl peptidase 4 as major components of matrix remodeling. PLoS One. 2015;10(3):e0122065.

78. Halberg N, et al. Hypoxia-inducible factor 1alpha induces fibrosis and insulin resistance in white adipose tissue. Mol Cell Biol. 2009;29(16):4467-4483.

79. Bruun JM, Lihn AS, Pedersen SB, Richelsen B. Monocyte chemoattractant protein-1 release is higher in visceral than subcutaneous human adipose tissue (AT): implication of macrophages resident in the AT. J Clin Endocrinol Metab. 2005;90(4):2282-2289.

80. Harman-Boehm I, et al. Macrophage infiltration into omental versus subcutaneous fat across different populations: effect of regional adiposity and the comorbidities of obesity. J Clin Endocrinol Metab. 2007;92(6):2240-2247.

81. Goossens GH, et al. Increased adipose tissue oxygen tension in obese compared with lean men is accompanied by insulin resistance, impaired adipose tissue capillarization, and inflammation. Circulation. 2011;124(1):67-76.

82. Goossens GH, Blaak EE. Adipose tissue dysfunction and impaired metabolic health in human obesity: a matter of oxygen? Front Endocrinol (Lausanne). 2015;6:55.

83. Torti FM, Dieckmann B, Beutler B, Cerami A, Ringold GM. A macrophage factor inhibits adipocyte gene expression: an in vitro model of cachexia. Science. 1985;229(4716):867-869.

84. Weisberg SP, McCann D, Desai M, Rosenbaum M, Leibel RL, Ferrante AW. Obesity is associated with macrophage accumulation in adipose tissue. J Clin Invest. 2003;112(12):1796-1808.

85. Cancello R, et al. Increased infiltration of macrophages in omental adipose tissue is associated with marked hepatic lesions in morbid human obesity. Diabetes. 2006;55(6):1554-1561.

86. Lilla J, Stickens D, Werb Z. Metalloproteases and adipogenesis: a weighty subject. Am J Pathol. 2002;160(5):1551-1554.

87. Chavey $C$, et al. Matrix metalloproteinases are differentially expressed in adipose tissue during obesity and modulate adipocyte differentiation. J Biol Chem. 2003;278(14):11888-11896.

88. Maquoi E, Munaut C, Colige A, Collen D, Lijnen HR. Modulation of adipose tissue expression of murine matrix metalloproteinases and their tissue inhibitors with obesity. Diabetes. 2002;51(4):1093-1101.

89. Gerin I, et al. Hyperphagia and obesity in female mice lacking tissue inhibitor of metalloproteinase-1. Endocrinology. 2009;150(4):1697-1704.

90. Sakamuri SSVP, et al. Absence of Tissue Inhibitor of Metalloproteinase-4 (TIMP4) ameliorates high fat diet-induced obesity in mice due to defective lipid absorption. Sci Rep. 2017;7(1):6210.

91. Green H, Meuth M. An established pre-adipose cell line and its differentiation in culture. Cell. 1974;3(2):127-133.

92. Ibrahimi A, Bonino F, Bardon S, Ailhaud G, Dani C. Essential role of collagens for terminal differentiation of preadipocytes. Biochem Biophys Res Commun. 1992;187(3):1314-1322.

93. Derosa G, et al. Matrix metalloproteinase-2 and -9 levels in obese patients. Endothelium. 2008;15(4):219-224.

94. Feola A, et al. Multifaceted breast cancer: the molecular connection with obesity. J Cell Physiol. 2017;232(1):69-77.

95. Catalán V, et al. Increased adipose tissue expression of lipocalin-2 in obesity is related to inflammation and matrix metalloproteinase-2 and metalloproteinase-9 activities in humans. J Mol Med. 2009;87(8):803-813.

96. Bouloumié A, Sengenès C, Portolan G, Galitzky J, Lafontan M. Adipocyte produces matrix metalloproteinases 2 and 9: involvement in adipose differentiation. Diabetes. 2001;50(9):2080-2086.

97. Roderfeld M, et al. Latent MMP-9 is bound to TIMP-1 before secretion. Biol Chem. 2007;388(11):1227-1234.

98. Vempati P, Karagiannis ED, Popel AS. A biochemical model of matrix metalloproteinase 9 activation and inhibition. J Biol Chem. 2007;282(52):37585-37596. 
99. Głowi冈ska-Olszewska B, Urban M. Elevated matrix metalloproteinase 9 and tissue inhibitor of metalloproteinase 1 in obese children and adolescents. Metab Clin Exp. 2007;56(6):799-805.

100. Kralisch S, Bluher M, Paschke R, Stumvoll M, Fasshauer M. Adipokines and adipocyte targets in the future management of obesity and the metabolic syndrome. Mini Rev Med Chem. 2007;7(1):39-45.

101. Kosmala W, Plaksej R, Przewlocka-Kosmala M, Kuliczkowska-Plaksej J, Bednarek-Tupikowska G, Mazurek W. Matrix metalloproteinases 2 and 9 and their tissue inhibitors 1 and 2 in premenopausal obese women: relationship to cardiac function. Int $J$ Obes (Lond). 2008;32(5):763-771.

102. Croissandeau G, Chrétien M, Mbikay M. Involvement of matrix metalloproteinases in the adipose conversion of 3T3-L1 preadipocytes. Biochem J. 2002;364(Pt 3):739-746.

103. Sillat T, Saat R, Pöllänen R, Hukkanen M, Takagi M, Konttinen YT. Basement membrane collagen type IV expression by human mesenchymal stem cells during adipogenic differentiation. J Cell Mol Med. 2012;16(7):1485-1495.

104. Zeng ZS, Cohen AM, Guillem JG. Loss of basement membrane type IV collagen is associated with increased expression of metalloproteinases 2 and 9 (MMP-2 and MMP-9) during human colorectal tumorigenesis. Carcinogenesis. 1999;20(5):749-755.

105. Mauney J, Volloch V. Human bone marrow-derived stromal cells show highly efficient stress-resistant adipogenesis on denatured collagen IV matrix but not on its native counterpart: implications for obesity. Matrix Biol. 2010;29(1):9-14

106. Chun TH. Peri-adipocyte ECM remodeling in obesity and adipose tissue fibrosis. Adipocyte. 2012;1(2):89-95.

107. Deryugina EI, et al. MT1-MMP initiates activation of pro-MMP-2 and integrin alphavbeta3 promotes maturation of MMP-2 in breast carcinoma cells. Exp Cell Res. 2001;263(2):209-223.

108. Holmbeck K, et al. MT1-MMP-deficient mice develop dwarfism, osteopenia, arthritis, and connective tissue disease due to inadequate collagen turnover. Cell. 1999;99(1):81-92.

109. Chun TH, Hotary KB, Sabeh F, Saltiel AR, Allen ED, Weiss SJ. A pericellular collagenase directs the 3-dimensional development of white adipose tissue. Cell. 2006;125(3):577-591.

110. Chun TH, et al. Genetic link between obesity and MMP14-dependent adipogenic collagen turnover. Diabetes. 2010;59(10):2484-2494

111. Sato-Kusubata K, Jiang Y, Ueno Y, Chun TH. Adipogenic histone mark regulation by matrix metalloproteinase 14 in collagen-rich microenvironments. Mol Endocrinol. 2011;25(5):745-753

112. Wang L, et al. Histone H3K9 methyltransferase G9a represses PPAR $\gamma$ expression and adipogenesis. EMBO J. 2013;32(1):45-59.

113. Pendás AM, et al. Diet-induced obesity and reduced skin cancer susceptibility in matrix metalloproteinase 19-deficient mice. Mol Cell Biol. 2004;24(12):5304-5313.

114. Belo VA, et al. Assessment of matrix metalloproteinase (MMP)-2, MMP-8, MMP-9, and their inhibitors, the tissue inhibitors of metalloproteinase (TIMP)-1 and TIMP-2 in obese children and adolescents. Clin Biochem. 2009;42(10-11):984-990.

115. Shin YH, Kim KE, Lee YJ, Nam JH, Hong YM, Shin HJ. Associations of matrix metalloproteinase (MMP)-8, MMP-9, and their inhibitor, tissue inhibitor of metalloproteinase-1, with obesity-related biomarkers in apparently healthy adolescent boys. Korean J Pediatr. 2014;57(12):526-532.

116. Tokunaga M, Inoue M, Jiang Y, Barnes RH, Buchner DA, Chun TH. Fat depot-specific gene signature and ECM remodeling of Sca1(high) adipose-derived stem cells. Matrix Biol. 2014;36:28-38.

117. Lenglet S, Mach F, Montecucco F. Role of matrix metalloproteinase-8 in atherosclerosis. Mediators Inflamm. 2013;2013:659282.

118. Deguchi JO, et al. Matrix metalloproteinase-13/collagenase-3 deletion promotes collagen accumulation and organization in mouse atherosclerotic plaques. Circulation. 2005;112(17):2708-2715.

119. Quillard T, Araújo HA, Franck G, Tesmenitsky Y, Libby P. Matrix metalloproteinase-13 predominates over matrix metalloproteinase- 8 as the functional interstitial collagenase in mouse atheromata. Arterioscler Thromb Vasc Biol. 2014;34(6):1179-1186

120. Shih CL, Ajuwon KM. Inhibition of MMP-13 prevents diet-induced obesity in mice and suppresses adipogenesis in 3T3-L1 preadipocytes. Mol Biol Rep. 2015;42(7):1225-1232.

121. Dalvie D, Cosker T, Boyden T, Zhou S, Schroeder C, Potchoiba MJ. Metabolism distribution and excretion of a matrix metalloproteinase-13 inhibitor, 4-[4-(4-fluorophenoxy)-benzenesulfonylamino]tetrahydropyran-4-carboxylic acid hydroxyamide (CP544439), in rats and dogs: assessment of the metabolic profile of CP-544439 in plasma and urine of humans. Drug Metab Dispos. 2008;36(9):1869-1883.

122. Kotzka J, et al. Sterol regulatory element binding proteins (SREBP)-1a and SREBP-2 are linked to the MAP-kinase cascade. J Lipid Res. 2000;41(1):99-108.

123. Greenberg AS, Obin MS. Obesity and the role of adipose tissue in inflammation and metabolism. Am J Clin Nutr. 2006;83(2):461S-465S

124. Risérus U, et al. Activation of peroxisome proliferator-activated receptor (PPAR)delta promotes reversal of multiple metabolic abnormalities, reduces oxidative stress, and increases fatty acid oxidation in moderately obese men. Diabetes. 2008;57(2):332-339.

125. Kawai T, et al. PPAR- $\gamma$ agonist attenuates renal interstitial fibrosis and inflammation through reduction of TGF- $\beta$. Lab Invest. 2009;89(1):47-58

126. Dantas AT, et al. The role of PPAR- $\gamma$ in systemic sclerosis. PPAR Res. 2015;2015:124624

127. Fang $\mathrm{F}$, et al. The adipokine adiponectin has potent anti-fibrotic effects mediated via adenosine monophosphate-activated protein kinase: novel target for fibrosis therapy. Arthritis Res Ther. 2012;14(5):R229.

128. Bansal T, et al. Arjunolic acid, a peroxisome proliferator-activated receptor $\alpha$ agonist, regresses cardiac fibrosis by inhibiting non-canonical TGF- $\beta$ signaling. J Biol Chem. 2017;292(40):16440-16462.

129. Koo JB, et al. Anti-fibrogenic effect of PPAR- $\gamma$ agonists in human intestinal myofibroblasts. BMC Gastroenterol. 2017;17(1):73

130. Lakatos HF, Thatcher TH, Kottmann RM, Garcia TM, Phipps RP, Sime PJ. The role of PPARs in lung fibrosis. PPAR Res. 2007;2007:71323

131. Leivonen SK, Ala-Aho R, Koli K, Grénman R, Peltonen J, Kähäri VM. Activation of Smad signaling enhances collagenase-3 (MMP-13) expression and invasion of head and neck squamous carcinoma cells. Oncogene. 2006;25(18):2588-2600.

132.Asano K, Shikama Y, Shoji N, Hirano K, Suzaki H, Nakajima H. Tiotropium bromide inhibits TGF- $\beta$-induced MMP production from lung fibroblasts by interfering with Smad and MAPK pathways in vitro. Int J Chron Obstruct Pulmon Dis. 2010;5:277-286

133. Wu M, Chen G, Li YP. TGF- $\beta$ and BMP signaling in osteoblast, skeletal development, and bone formation, homeostasis and disease. Bone Res. 2016;4:16009. 
134. Morizane Y, et al. AMP-activated protein kinase suppresses matrix metalloproteinase-9 expression in mouse embryonic fibroblasts. J Biol Chem. 2011;286(18):16030-16038.

135. MacLaren RE, Cui W, Lu H, Simard S, Cianflone K. Association of adipocyte genes with ASP expression: a microarray analysis of subcutaneous and omental adipose tissue in morbidly obese subjects. BMC Med Genomics. 2010;3:3.

136. Alexander CM, Selvarajan S, Mudgett J, Werb Z. Stromelysin-1 regulates adipogenesis during mammary gland involution. J Cell Biol. 2001;152(4):693-703.

137. Wu Y, Lee MJ, Ido Y, Fried SK. High-fat diet-induced obesity regulates MMP3 to modulate depot- and sex-dependent adipose expansion in C57BL/6J mice. Am J Physiol Endocrinol Metab. 2017;312(1):E58-E71.

138. Chen SZ, et al. The miR-181d-regulated metalloproteinase Adamts1 enzymatically impairs adipogenesis via ECM remodeling. Cell Death Differ. 2016;23(11):1778-1791.

139. Voros G, Maquoi E, Collen D, Lijnen HR. Differential expression of plasminogen activator inhibitor-1, tumor necrosis factor-alpha, TNF-alpha converting enzyme and ADAMTS family members in murine fat territories. Biochim Biophys Acta. 2003;1625(1):36-42.

140. Rankinen T, et al. The human obesity gene map: the 2005 update. Obesity (Silver Spring). 2006;14(4):529-644.

141. Lin D, Chun TH, Kang L. Adipose extracellular matrix remodelling in obesity and insulin resistance. Biochem Pharmacol. 2016;119:8-16.

142. Muir LA, et al. Adipose tissue fibrosis, hypertrophy, and hyperplasia: Correlations with diabetes in human obesity. Obesity (Silver Spring). 2016;24(3):597-605.

143. Meena VP, et al. Relationship of adipocyte size with adiposity and metabolic risk factors in Asian Indians. PLoS One. 2014;9(9):e108421.

144. Lackey DE, et al. Contributions of adipose tissue architectural and tensile properties toward defining healthy and unhealthy obesity. Am J Physiol Endocrinol Metab. 2014;306(3):E233-E246.

145. Guglielmi V, et al. Omental adipose tissue fibrosis and insulin resistance in severe obesity. Nutr Diabetes. 2015;5:e175.

146. Michaud A, et al. Relevance of omental pericellular adipose tissue collagen in the pathophysiology of human abdominal obesity and related cardiometabolic risk. Int J Obes (Lond). 2016;40(12):1823-1831.

147. Abdennour M, et al. Association of adipose tissue and liver fibrosis with tissue stiffness in morbid obesity: links with diabetes and BMI loss after gastric bypass. J Clin Endocrinol Metab. 2014;99(3):898-907.

148. Lawler HM, Underkofler CM, Kern PA, Erickson C, Bredbeck B, Rasouli N. Adipose tissue hypoxia, inflammation, and fibrosis in obese insulin-sensitive and obese insulin-resistant subjects. J Clin Endocrinol Metab. 2016;101(4):1422-1428.

149. Alcalá M, et al. Vitamin E reduces adipose tissue fibrosis, inflammation, and oxidative stress and improves metabolic profile in obesity. Obesity (Silver Spring). 2015;23(8):1598-1606.

150. Zeve D, Tang W, Graff J. Fighting fat with fat: the expanding field of adipose stem cells. Cell Stem Cell. 2009;5(5):472-481.

151. Lee MJ, Wu Y, Fried SK. Adipose tissue remodeling in pathophysiology of obesity. Curr Opin Clin Nutr Metab Care. 2010;13(4):371-376

152. Cinti S, et al. Adipocyte death defines macrophage localization and function in adipose tissue of obese mice and humans. J Lipid Res. 2005;46(11):2347-2355.

153. Wang QA, Tao C, Gupta RK, Scherer PE. Tracking adipogenesis during white adipose tissue development, expansion and regeneration. Nat Med. 2013;19(10):1338-1344.

154. Rosen ED, Spiegelman BM. What we talk about when we talk about fat. Cell. 2014;156(1-2):20-44.

155. McCulloch LJ, et al. COL6A3 is regulated by leptin in human adipose tissue and reduced in obesity. Endocrinology. 2015;156(1):134-146.

156. Bouchard C, et al. The response to long-term overfeeding in identical twins. N Engl J Med. 1990;322(21):1477-1482.

157. Sandholt CH, Hansen T, Pedersen O. Beyond the fourth wave of genome-wide obesity association studies. Nutr Diabetes. 2012;2:e37.

158. Turnbaugh PJ, Ley RE, Mahowald MA, Magrini V, Mardis ER, Gordon JI. An obesity-associated gut microbiome with increased capacity for energy harvest. Nature. 2006;444(7122):1027-1031.

159. Bäckhed F, et al. The gut microbiota as an environmental factor that regulates fat storage. Proc Natl Acad Sci U S A. 2004;101(44):15718-15723.

160. Wernstedt Asterholm I, Scherer PE. Fibrosis-streaks and splatters: Some things are not always what they seem to be. Obesity (Silver Spring). 2016;24(3):552-553.

161.Park J, Scherer PE. Adipocyte-derived endotrophin promotes malignant tumor progression. J Clin Invest. 2012;122(11):4243-4256.

162. Sun G, et al. Reduced serum milk fat globule-epidermal growth factor 8 (MFG-E8) concentrations are associated with an increased risk of microvascular complications in patients with type 2 diabetes. Clin Chim Acta. 2017;466:201-206.

163. Rodriguez M, et al. Collagen VI and endotrophin regulate glucose homeostasis in skeletal muscle. Neuromuscul Disord. 2016;26(supp1 2):S188.

164. Sun S, Ji Y, Kersten S, Qi L. Mechanisms of inflammatory responses in obese adipose tissue. Annu Rev Nutr. 2012;32:261-286.

165. Reilly SM, Saltiel AR. Adapting to obesity with adipose tissue inflammation. Nat Rev Endocrinol. 2017;13(11):633-643.

166. Nishimura S, Manabe I, Nagai R. Adipose tissue inflammation in obesity and metabolic syndrome. Discov Med. 2009;8(41):55-60.

167. Blüher M. Adipose tissue inflammation: a cause or consequence of obesity-related insulin resistance? Clin Sci (Lond). 2016;130(18):1603-1614.

168. Le Dour C, Wu W, Béréziat V, Capeau J, Vigouroux C, Worman HJ. Extracellular matrix remodeling and transforming growth factor- $\beta$ signaling abnormalities induced by lamin A/C variants that cause lipodystrophy. J Lipid Res. 2017;58(1):151-163.

169. Spencer M, et al. Adipose tissue macrophages in insulin-resistant subjects are associated with collagen VI and fibrosis and demonstrate alternative activation. Am J Physiol Endocrinol Metab. 2010;299(6):E1016-E1027.

170. Zhang F, et al. TGF- $\beta$ induces M2-like macrophage polarization via SNAIL-mediated suppression of a pro-inflammatory phenotype. Oncotarget. 2016;7(32):52294-52306.

171. Gong D, Shi W, Yi SJ, Chen H, Groffen J, Heisterkamp N. TGF $\beta$ signaling plays a critical role in promoting alternative macrophage activation. BMC Immunol. 2012;13:31. 
172. Spencer M, et al. Adipose tissue extracellular matrix and vascular abnormalities in obesity and insulin resistance. J Clin Endocrinol Metab. 2011;96(12):E1990-E1998.

173. Lumeng CN, Bodzin JL, Saltiel AR. Obesity induces a phenotypic switch in adipose tissue macrophage polarization. $J C l i n$ Invest. 2007;117(1):175-184.

174. Pellegrinelli V, et al. Human adipocyte function is impacted by mechanical cues. J Pathol. 2014;233(2):183-195.

175. Lee MJ, Wu Y, Fried SK. Adipose tissue heterogeneity: implication of depot differences in adipose tissue for obesity complications. Mol Aspects Med. 2013;34(1):1-11.

176. Morandi EM, Verstappen R, Zwierzina ME, Geley S, Pierer G, Ploner C. ITGAV and ITGA5 diversely regulate proliferation and adipogenic differentiation of human adipose derived stem cells. Sci Rep. 2016;6:28889.

177. Lancha A, et al. Osteopontin deletion prevents the development of obesity and hepatic steatosis via impaired adipose tissue matrix remodeling and reduced inflammation and fibrosis in adipose tissue and liver in mice. PLoS One. 2014;9(5):e98398

178. Liu J, DeYoung SM, Zhang M, Zhang M, Cheng A, Saltiel AR. Changes in integrin expression during adipocyte differentiation. Cell Metab. 2005;2(3):165-177.

179. Lin JZ, Rabhi N, Farmer SR. Myocardin-related transcription factor a promotes recruitment of ITGA5+ profibrotic progenitors during obesity-induced adipose tissue fibrosis. Cell Rep. 2018;23(7):1977-1987.

180. Farnier C, et al. Adipocyte functions are modulated by cell size change: potential involvement of an integrin/ERK signalling pathway. Int J Obes Relat Metab Disord. 2003;27(10):1178-1186.

181. Pope BD, Warren CR, Parker KK, Cowan CA. Microenvironmental control of adipocyte fate and function. Trends Cell Biol. 2016;26(10):745-755.

182. Meakin PJ, et al. Mice lacking $\beta 2$-integrin function remain glucose tolerant in spite of insulin resistance, neutrophil infiltration and inflammation. PLoS One. 2015;10(9):e0138872.

183. Roumans NJ, Vink RG, Fazelzadeh P, van Baak MA, Mariman EC. A role for leukocyte integrins and extracellular matrix remodeling of adipose tissue in the risk of weight regain after weight loss. Am J Clin Nutr. 2017;105(5):1054-1062

184. Khalifeh-Soltani A, et al. Mfge8 promotes obesity by mediating the uptake of dietary fats and serum fatty acids. Nat Med. 2014;20(2):175-183

185. Khalifeh-Soltani A, et al. Mfge8 regulates enterocyte lipid storage by promoting enterocyte triglyceride hydrolase activity. JCI Insight. 2016;1(18):e87418.

186. Florys B, Głowińska B, Urban M, Peczyńska J. Metalloproteinases MMP-2 and MMP-9 and their inhibitors TIMP-1 and TIMP-2 levels in children and adolescents with type 1 diabetes [in Polish]. Endokrynol Diabetol Chor Przemiany Materii Wieku Rozw. 2006;12(3):184-189. 